\title{
Study on Computer Software Applied in Teaching of Design of Chemical Engineering Principles
}

\author{
Tingting Tang, Jun Wang* \\ Department of Chemistry and Chemical Engineering, Zhoukou Normal University, Zhoukou, China \\ Email: ${ }^{\star}$ zk-wangjun@163.com
}

How to cite this paper: Tang, T.T. and Wang, J. (2019) Study on Computer Software Applied in Teaching of Design of Chemical Engineering Principles. Open Access Library Journal, 6: e5292. https://doi.org/10.4236/oalib.1105295

Received: February 25, 2019

Accepted: March 24, 2019

Published: March 27, 2019

Copyright $\odot 2019$ by author(s) and Open Access Library Inc.

This work is licensed under the Creative Commons Attribution International License (CC BY 4.0).

http://creativecommons.org/licenses/by/4.0/

\section{(c) () Open Access}

\begin{abstract}
Design of chemical engineering principles is an essential course to improve chemical engineering major students' capacity of engineering design and practical application. This paper mainly introduces the application of some popular calculation software or application software in the teaching of chemical engineering principle curriculum design. The basic functions and characteristics and the significance and existing problems of using software for teaching are discussed in this paper in order to promote the reform of the curriculum system of chemical engineering principle curriculum design.
\end{abstract}

\section{Subject Areas}

Chemical Engineering \& Technology

\section{Keywords}

Computer Software, Design of Chemical Engineering Principles,

Teaching Reform, Application

\section{Introduction}

The course design of chemical engineering principle is an engineering subject with strong practicality. Its purpose is to train the students' ability and to carry out chemical engineering process design by comprehensively applied the principles of chemical engineering with the basic knowledge of related prerequisite courses [1]. Through the study of the course, students can get familiar with the basic content of the course design, master the basic procedures and methods of chemical engineering design, understand the complexity of practical engineering problems, combine theory with practice, and get a basic training of chemical 
engineering design. In modern engineering design, computer-aided design has already completely replaced manual calculation and design. Some popular application softwares with its powerful numerical value, symbolic operation function and vivid image processing ability are widely applied instead of the traditional way of using pen and paper for design operation [2] [3] [4].

Under the new developing background, the importance of computer and application software to the aided teaching of chemical engineering principle course design is more and more prominent. In this paper, the authors will elaborate the profound influence and the practical applications of computer aided teaching.

\section{Discussion}

\subsection{The Influence of Computer Technology on the Course Design Teaching of Chemical Engineering Principles}

With the advent of the information age of education, the application of computing software and other sciences are more and more deeply penetrated into each other, and there has been a breakthrough in the way of using or computing software to assist teaching. The exploration and improvement of design of chemical engineering principles of computer aided chemical engineering have appeared constantly. Many colleges and universities have carried out the experiment and practice of computer aided teaching in the course design of the chemical engineering principles. According to the technological conditions and design conditions, the course design requires students to comprehensively apply the theoretical knowledge of chemical principles and determine the type of equipment, calculate the size of equipment and design the structure of equipment through complex engineering calculation. There are many calculation methods and formulas, including empirical formula and semi-empirical formula, used in the course design of chemical engineering principles.

However, due to the complex calculation problems such as trial error and iteration often involved in the process of process calculation, manual calculation is not only time-consuming and laborious, but also has poor calculation accuracy, so students are generally reluctant to adopt it. Therefore, the use of some computing software to help complete the design of computing design has become a new direction of teaching development [5].

\subsection{The Application of Calculation Software or Application Software in the Course Design of Chemical Engineering Principles}

At present, the commonly used software in the principles of chemical engineering course design is $\mathrm{C}++$, Matlab, AutoCAD, Aspen Plus and Pro/II, etc. This paper compares and analyzes various kinds of popular calculation or chemical engineering software in order to find out its development trend and a development direction suitable for design teaching. 
Excel is an important part of the office software Office 2016, and it is also one of the commonly known and understood computing software by students and teachers. It is characterized by powerful data processing and drawing analysis functions, especially the functions of solving single variables, simple functions and automatic filling. It can turn complex programming or iterative calculation process into convenient menu and toolbar operations. Some parameters can be obtained by the automatic filling function of Excel as long as the formula is entered once, which greatly reduces the burden of calculation board by board or multiple trial and error. For example, many parameters such as the bubble and dew point of binary ideal solution, equilibrium composition, reflux ratio, number of theoretical plates and gas-liquid phase composition of each layer plate can be rapidly calculated by using these built-in functions of Excel software in the design process of distillation column.

$\mathrm{C}++$ language has the advantages of powerful computing function and high execution efficiency. It is a traditional computing language commonly used by designers. In particular, the circular calculation function of $\mathrm{C}++$ can easily solve the theoretical plate number calculation problem in the design of distillation tower. The calculation function of Matlabis was mainly manifested in curve fitting, equation solving, numerical integration and graphic demonstration. It can realize several problems in the fields of number calculation, data analysis, optimization, statistics, automatic control, signal processing and image processing. Computing language used in the course design is the premise of requires teachers and students have a certain ability of programming, debugging, but due to the computer class students have fewer computer programming training, students' ability in modeling and programming ability is still slightly insufficient, combined with principles of chemical engineering course design time is limited, if the students spend much time on calculation programming and debugging, it is bound to fail to finish curriculum design task within the allotted time.

Aspen Plus and Pro/II belong to large general process simulation software, with user-friendly interface and rich help system. The software is applied to the design of continuous distillation column. DSTWU model in Aspen Plus model library can be used to calculate the distillation column simply. In the use of Pro/II Shortcut forthright calculation module, it can calculate the minimum reflux ratio of distillation column and the minimum theoretical plate number, thus it is concluded that the actual reflux ratio, the theoretical plate number and the feed position. Finally, Distillation module is used to carry out strict calculation and complete the design of distillation tray.

\section{Conclusion}

The use of general process simulation software to assist design is the future development direction of design courses. This method can make the curriculum design more close to the engineering practice, and help students to improve the awareness and ability of computer-aided design, and is conducive to the 
combination of teaching and practice, but also for teachers to guide the design work has brought convenience.

\section{Conflicts of Interest}

The authors declare no conflicts of interest regarding the publication of this paper.

\section{References}

[1] Jiao, W.Z., Liu, Y.Z., Yuan, Z.G., et al. (2014) Research and Exploration on Experimental Teaching Mode of Chemical Engineering Based on Engineering Practice Ability. Experimental Technology and Management, 31, 165-168.

[2] Wu, Q. and Wang, Y.-J. (2018) Research on Chemical Industry Automation Control and Chemical Instrumentation. Technology and Equipment, 44, 96-97.

[3] Li, J.L., Jia, L.H. and Sui, G.Z. (2010) Teaching Reform on the Curriculum of Chemical Engineering Design. Higher Education in Chemical Engineering, No. 5, 64-66.

[4] Tian, H.-Y. (2017) The Application of Computer in the Teaching of Chemical Reaction Engineering. Chemical Engineering \& Equipment, No. 3, 227-229.

[5] Lai, W.-D. and Zhong, L. (2012) Review on Computer Software Applied in Teaching of Design of Chemical Engineering Principles. Higher Education in Chemical Engineering, No. 1, 63-65. 